\title{
Effect of arbuscular mycorrhizal fungi and water stress on ultrastructural change of glandular hairs and essential oil compositions in Ocimum gratissimum
}

\author{
Zakaria Hazzoumi, Youssef Moustakime and Khalid Amrani Joutei
}

\begin{abstract}
Background: The objective of this work is to study the influence of arbuscal mycorrhizal fungi (Glomus intraradices) and water stress on the ultrastructural change of basil glandular hair and also on the essential oil synthesis, especially on the isomerization of the two main compounds methyl chavicol and trans-anethole.

Results: The results of this study show that mycorrhization increases the yield of essential oils, with a maximum recorded in mycorrhizal stressed plants (0.33\%) and a minimum among non-mycorrhizal unstressed plants (0.22\%). Oxygenated monoterpenes represent the main family of essential oils. Furthermore, the chemical composition of these essential oils changed under the condition in which the plant is. However, the main compound methyl chavicol was found to be at maximum concentration (93\%) in mycorrhizal stressed plants and minimum in non-mycorrhizal stressed plants (84\%). Contrariwise, its isomer trans-anethole reached the maximum (8\%) among non-mycorrhizal non-stressed plants and minimum (2\%) in non-mycorrhizal stressed plants.

Conclusion: Ocimum gratissimum L. leaves showed the presence of two types of peltate glands: the first one with 4 secreting cells and the second with 8 secreting cells. The diameter of these glands changed with the hydric state of plants; in the absence of mycorrhization, stress causes a decrease in the extracellular cavity diameter of glandular trichomes and their deflation which would cause a concentration of essential oil in the glands.
\end{abstract}

Keywords: AMF, Glomus intraradices, m-Chavicol, t-Anethole, Glandular trichomes, Water stress, Extracellular cavities

\section{Background}

Water stress causes significant changes in essential oil yield and composition in several aromatic plants [26]. There has been a reduction of yield in the rosemary (Rosmarinus officinalis L.) and anise (Pimpinella anisum L.) $[29,36]$ following a water deficit, whereas in pepper (Capsicum annuum L.), the water deficit led to an increase in the essential oil yield.

In Ocimum basilicum plant, water stress increases the essential oil yield and the levels of major compounds

\footnotetext{
*Correspondence: Zakaria.hazzoumi@yahoo.fr;

Zakaria.hazzoumi@usmb.ac.ma

Laboratory of Bioactive Molecules, Faculty of Science and Technology, Sidi Mohamed Ben Abdellah University, Road of Imouzzer, B. P. 2202, Fez, Morocco
}

(linalool and methyl chavicol) [14]. Hendawy and Khalid [12] confirmed these results in Salvia officinalis. Similarly, Solinas et al. [30] confirmed that water stress strongly affected the secondary metabolism of plants in a general way and essential oils in a specific way.

In our previous work performed on Ocimum gratissimum L. plants, Hazzoumi et al. [10] have confirmed that water stress may slightly increase the essential oil yield to an average of $10 \%$.

Furthermore, mycorrhizae strongly affect the plant metabolism, leading to the induction of chemical defense [24]. This change affects the synthesis of several families of molecules, terpenoids [25], essential oils (Copetta et al. $[2,3])$, and glucosinolates [33].Gupta et al. [8] reported that, in Mentha arvensis L., mycorrhizal inoculation 
significantly increased the essential oil content. Freitas et al. [4] have also observed that the inoculation of $M$. arvensis with mycorrhizal fungi leads to an increase in the essential oil yield by $89 \%$ in the same way as the major compound (menthol). In O. gratissimum plants inoculated with Glomus intraradices, Hazzoumi et al. [10] have shown that the levels of essential oils increased significantly and related this increase to the abundance of secreting glands in leaves.

The accumulation of essential oils in plants is usually limited to specialized secretory structures which are present in several different types, namely glandular trichomes. They are multicellular epidermal hairs found in some families like the Lamiaceaes, Asteraceaes, and Solanaceae, which secrete terpenes in the extracellular cavity at the apex of the trichome [34, 35].

The storage of terpenoid in these structures can be used to limit the toxicity risk to the plant itself, because it is proven that many terpenoids are potentially toxic to plant tissues when monoterpenes are released to the surrounding cells [20]. Injuries were also found when some sesquiterpenes were artificially deposited on sheets during tests on their ability to deter herbivores [23]. Therefore, sequestration of terpenoids in specific compartments by sensitive metabolic processes can be essential to avoid harmful effects. However, the morphology of these structures varies with the irrigation conditions and also depends on the toxicity of intracuticular content.

According to Gershenzon et al. [6], the glandular trichome consists of several cells providing different functions. The essential oils secreted by secretory cells are passed through a space situated at the apex of subcuticular trichome and get accumulated; however, the basal cells provide attachment to the skin structure (Fig. 1).

The question of gland maturity and the number of secreting cells per glands remains a subject of debate between scientists [34, 35]. It is found that basil plants have 4 or more secreting cells per gland, whose maturity is reflected by a slight folding in the cuticle. However, Gang et al. [5] have limited the number of secreting cells to 4 and showed that folded glands do not present

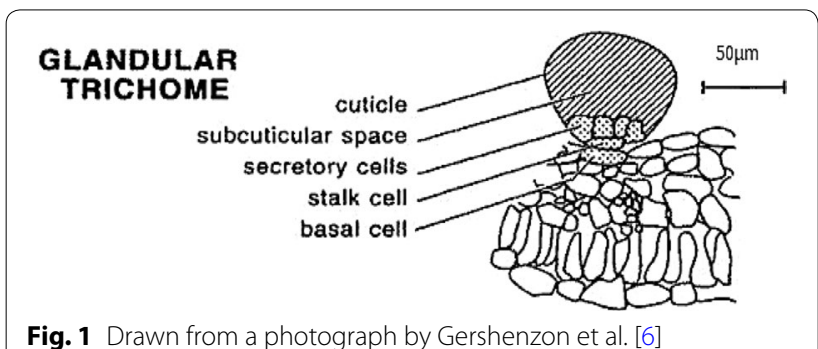

Fig. 1 Drawn from a photograph by Gershenzon et al. [6] any terpenoid content. According to these authors, folding allows the quadratic subdivision of the cuticle due to the presence of 4 secreting cells and it is an index of non-maturation. Until the filling of the cuticular cavity by essential oils, this division tends to disappear.

In this study, we tried to evaluate the effect of water stress and AMF by G. intraradices on the essential oil synthesis, in terms of yield and chemical composition and also the morphology of the secretory glands of these essential oils, in an aromatic plant, basilO. gratissimum $\mathrm{L}$, which is widely used in the traditional pharmacopoeia and cosmetics industry in Morocco .

\section{Methods}

\section{Plant material (germination and culture)}

The basil (O. gratissimum L.) seeds were disinfected by a passage in ethanol $95 \%$ for $1 \mathrm{~min} 30 \mathrm{~s}$ and immersed in mercury hypochlorite solution (1\%) for 3-4 min. Seeds were then rinsed several times in sterile distilled water before being placed on an agar medium or on a filter paper moistened with sterile distilled water in Petri dishes. The petri dishes were placed in an oven at $26^{\circ} \mathrm{C}$, in the dark, for seed germination.

After germination, seedlings were transplanted into plastic pots ( $3 \mathrm{~kg}$ capacity) containing the growth substrate, with 50-60 plants per pot, and were grown in the greenhouse at temperature between 26 and $34{ }^{\circ} \mathrm{C}$. The basil plants (M or NM) are watered daily. After the 50th day, the plants are subjected to different water regimes:

a. Water regime unstressed (NS): the plants are not deprived of water throughout their growth

b. Application of water stress (S): plants are deprived of water for 2 weeks.

\section{Estimation of mycorrhizal root infection}

The identification of mycorrhizal root infection is realized by optical microscopy through a technique not vital staining with trypan blue (TB), described by Hayman [9] revealing the set of fungal biomass.

Root samples, taken at random, are thoroughly rinsed to remove the adhering substrate. Then, the root fragments are digested in a solution of $10 \%$ potassium hydroxide $(\mathrm{KOH})$ for $45 \mathrm{~min}$ at $90{ }^{\circ} \mathrm{C}$ in an oven, in order to empty the cell of their cytoplasmic contents which confer coloring. Then, the roots are thoroughly rinsed with distilled water and placed in the lactophenol trypan blue solution (0.5\%) at $90{ }^{\circ} \mathrm{C}$ in the oven for $15 \mathrm{~min}$.

\section{Estimation of mycorrhization}

We used the technique described by Trouvelot et al. [32]. This method allows to judge the state of mycorrhization 
and reflects the potential of the symbiotic system. Colored roots were cut into fragments of approximately $1 \mathrm{~cm}$ length. Thirty random fragments are assembled and crushed between slide and coverslip in lactoglycerol, with 15 fragments per slide. Endomycorrhizal infection is observed under the light microscope. Several parameters are evaluated as follows:

$$
F \%=(\text { Number of mycorrhizal fragments } / N) \times 100,
$$

where $(F \%)$ is the frequency of mycorrhization reflecting the importance and the percentage of fragments of infected roots, with $N$ as the total number of root fragments observed.

$(M \%)$ is the intensity of the cortex colonization expressing the portion of the cortex colonized with respect to the entire root system, with $n 5, n 4, \ldots, n 1$ as the number of fragments, respectively, denoted as $5,4, \ldots, 1$,

$$
\% M=(95 n 5+70 n 4+30 n 3+10 n 2+n 1) / N .
$$

\section{Mycorrhizal intensity}

$\% m=M \times($ total number $) /$

(number of mycorrhizal fragments $)=M \times 100 / F$.

$(A \%)$ is the frequency of arbuscular in roots:

$$
\% A=a \times(M / 100) .
$$

The arbuscular intensity of the mycorrhizal part is estimated as follows:

$$
\% a=(100 m A 3+50 m A 2+10 m A 1) / 100
$$

where $m A 3, m A 2$, and $m A 1 \% \mathrm{~m}$ are, respectively, assigned $A 3, A 2$, and $A 1$ notes, and where $m A 3=((95 n 5 A 370 n 4 A 3+++30 n 3 A 35 n 2 A 3 n 1 A 3$ $+) /$ mycorrhizal number $) \times 100 / \mathrm{m}$.

Similarly for A2 and A1.

\section{Relative water contents (RWC)}

The relative water content (RWC) is measured on the full development of 7 th or 8 th leaf using the following formula according to Bandurska [1]:

$$
\mathrm{RWC} \%=100 \times[(\mathrm{FW}-\mathrm{DW}) /(\mathrm{WT}-\mathrm{DW})],
$$

where FW represents the weight of fresh leaf material, WT the the weight of fresh material from the turgid leaf which was submerged in distilled water for $4 \mathrm{~h}$, and DW represents the dry weight of the sheet material placed in an oven at $70{ }^{\circ} \mathrm{C}$ for $24 \mathrm{~h}$.

\section{Environmental scanning electron microscope}

The observations were performed using a Quanta 200 (FEI company) Environmental Scanning Electron Microscope. The microscope is equipped with a tungsten electron gun. The analyses are carried out under a partial pressure of water vapor.

\section{Specifications/capabilities}

It is capable of functioning under high-vacuum, low-vacuum, and environmental vacuum modes and its specifications include field emission gun, energy-dispersive silicon drift X-ray detector, cathodoluminescence system, backscattered electron detector, peltier-cooled stage, scanning transmission detector, wet scanning transmission detector, large field detector, gaseous analytical detector, gaseous backscatter detector, low-vacuum and low-voltage cones, and gaseous secondary electron detector.

\section{Light microscopy}

Optika B-350 Trinocular Biological Microscope is connected to camera AIPTEK Z600 (resolution 1080 Megapixels) and is equipped with two different types of optical system: anti-fungus $160 \mathrm{~mm}$ standard system and infinity corrected system (IOS). In both cases, the field diameter of the system is $20 \mathrm{~mm}$, macro- and micrometric focusing (graduated $0.002 \mathrm{~mm}$ ) wth coaxial controls.

\section{Extraction of essential oils}

Dried aerial parts (100 g) of O. gratissimum plants were submitted to hydrodistillation with a Clevenger-type apparatus and extracted with $2 \mathrm{~L}$ of water for $180 \mathrm{~min}$ (until no more essential oil was obtained). The essential oil was collected, dried under anhydrous sodium sulphate, and stored at $4{ }^{\circ} \mathrm{C}$ until analysis. The essential oil yield is calculated using the following formula:

$\mathrm{YEO}(\mathrm{ml} / 100 \mathrm{~g} \mathrm{Dm})=(V / \mathrm{Dm} \times 100) \pm(\Delta V / \mathrm{Dm} \times 100)$

where Y.E.O represents the essential oil yield of dry matter, $V$ the volume of essential oils collected ( $\mathrm{ml}), \Delta V$ the reading error, and Dm represents the dry plant mass (g).

\section{GC/MS analysis}

Gas chromatography (GC) analyses were performed on a Hewlett-Packard (HP 6890) gas chromatograph (FID), equipped with a $5 \%$ phenyl methyl silicone HP-5 capillary column $(30 \mathrm{~m} \times 0.25 \mathrm{~mm} \times$ film thickness $0.25 \mu \mathrm{m})$. The column temperature was programed at $50{ }^{\circ} \mathrm{C}$ for $5 \mathrm{~min}$ and then increased to $200{ }^{\circ} \mathrm{C}$ with a flow rate of $4{ }^{\circ} \mathrm{C} / \mathrm{min}$. Gas chromatography conditions were as follows: N2 as carrier 
gas $(1.8 \mathrm{ml} / \mathrm{min}$ ); split mode was used (Flow: $72.1 \mathrm{ml} / \mathrm{min}$, ratio $1 / 50)$; the temperature of injector and detector was $250{ }^{\circ} \mathrm{C}$; and the final hold time was $48 \mathrm{~min}$. The machine was led by a computer system type "HP ChemStation," managing the functioning of the machine and allowing to follow the evolution of chromatographic analyses. Diluted samples ( $1 / 20$ in methanol) of $1 \mu \mathrm{l}$ were injected manually.

GC/MS qualitative analyses were performed on a Hewlett-Packard equipped with a HP-5MS (Crosslinked $5 \%$ PHME Siloxane) capillary column $(30 \mathrm{~m} \times 0.25 \mathrm{~mm}$ i.d, $0.25 \mu \mathrm{m}$ film thickness) and coupled with a mass spectrometer (HP 5973). The temperature was programmed from 50 to $250{ }^{\circ} \mathrm{C}$ at $2{ }^{\circ} \mathrm{C} / \mathrm{min}$. The carrier gas was $\mathrm{He}(1.5 \mathrm{ml} / \mathrm{min})$, and a split mode was used (Flow: $112 \mathrm{ml} / \mathrm{min}$, ratio: 1/74.7). The different compounds were confirmed by reference to their MS identities (Library of NIST/EPA/NIH MASS SPECTRAL LIBRARY Version 2.0, built Jul 1, 2002). MS operating parameters were ionization voltage, $70 \mathrm{eV}$; ion source temperature, $230{ }^{\circ} \mathrm{C}$; and scan mass, 35-450.

\section{Statistical analysis}

One-way analysis of variance was carried out for each parameter studied. Tukey's post hoc multiple mean comparison test was used to test for significant differences between treatments (at $p \leq 0.05 \%$ ). Univariate analysis was used to test significant differences in treatments, accessions, and their interaction for an individual parameter. All statistical analyses were performed with IBM. SPSS statistics, Version 19. The results of each experiment (biochemical assays) were repeated three times, and 20 times for mycorrhizal intensity assays.

\section{Results}

\section{Mycorrhizal colonization}

Table 1 shows mycorrhizal colonization of basil plants subjected to continuous irrigation (NS) and water stress $(S)$ after treatment with trypan blue. Mycorrhizal intensity $(M \%)$ and arbuscular richness $(A \%)$ showed no differences between the stressed plant and unstressed plant. Contrariwise, control plants which were grown in a sterilized soil showed no mycorrhizal colonization.

Table 1 Mycorrhizal colonization of basil (O. gratissimum) roots subjected to continuous irrigation (NS) and water stress $(S)$; the values followed by different letters are significantly different $(p=0.05)$

\begin{tabular}{lrr}
\hline Mycorrhizal colonization & \multicolumn{1}{l}{ NS } & \multicolumn{1}{l}{$\boldsymbol{l}$} \\
\hline Mycorrhizal frequency (F\%) & $78.5 \pm 2.75$ & $77.3 \pm 2.44$ \\
Mycorrhizal intensity (M\%) & $35 \pm 2.32$ & $32 \pm 1.88$ \\
Arbuscular richness (A\%) & $20 \pm 1.12$ & $17 \pm 0.95$ \\
\hline
\end{tabular}

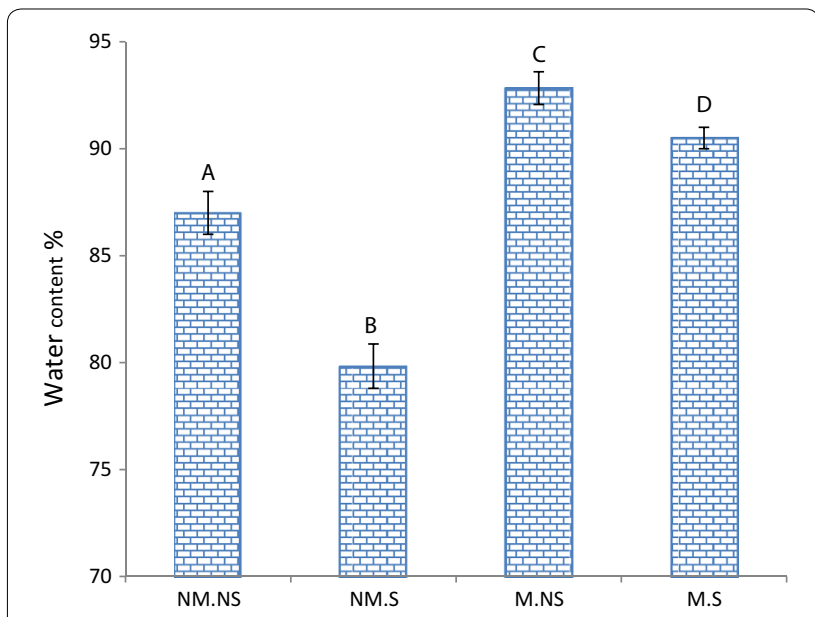

Fig. 2 Water contents in basil plant (O. gratissimum L.) inoculated with ( $G$. intraradices) $(M)$ or not (NM) and subjected to water stress $(S)$ or not (NS). The values followed by different letters are significantly different $(p=0.05)$

Effect of mycorrhizae and water stress on water contents Mycorrhization and water stress influenced water contents significantly in basil plant; we recorded a significant variation between the different treatments (Fig. 2). In M.NS plants, mycorrhizal fungi increase the levels of water to up to $93 \%$. Non-mycorrhizal plants showed the lowest levels with a dramatic decrease recorded in NM.S plants (81\%). In MS plants, there has been relatively high water content $(91 \%)$ reflecting the role of mycorrhizal fungi in withstanding the water deficit in stressed plants.

\section{Microscopy observations}

Observations by light microscopy of a cross section of the central portion of basil plants (O. gratissimum) which received normal irrigation show the presence of two kinds of peltate glands on the ventral side: glands having 4 secreting cells (Fig. 3a) and glands with 8 secreting cells (Fig. 3b, c). These glands have a swollen appearance indicating adequate irrigation of the plants.

The light microscopy also shows significant differences in the diameter, structure, and color of these structures: unstressed plants, mycorrhizal or not, have large glands having an inflated shape and are greenish (Fig. 4a, c). Contrariwise, stressed plants have glands with a reddish coloration (Fig. 4c, d) with a small structure, and a deflated aspect in NM plants (Fig. 4c). These results obtained in light microscopy are confirmed by environmental scanning electron microscopy (Fig. 5).

The mycorrhization causes a significant increase in the diameter of these cavities (Fig. 5c, d), while nonmycorrhizal plants have cavities with small diameter and this is regardless of the hydration level of plant (Fig. 5a, b). Water stress causes further deflation of these cavities 


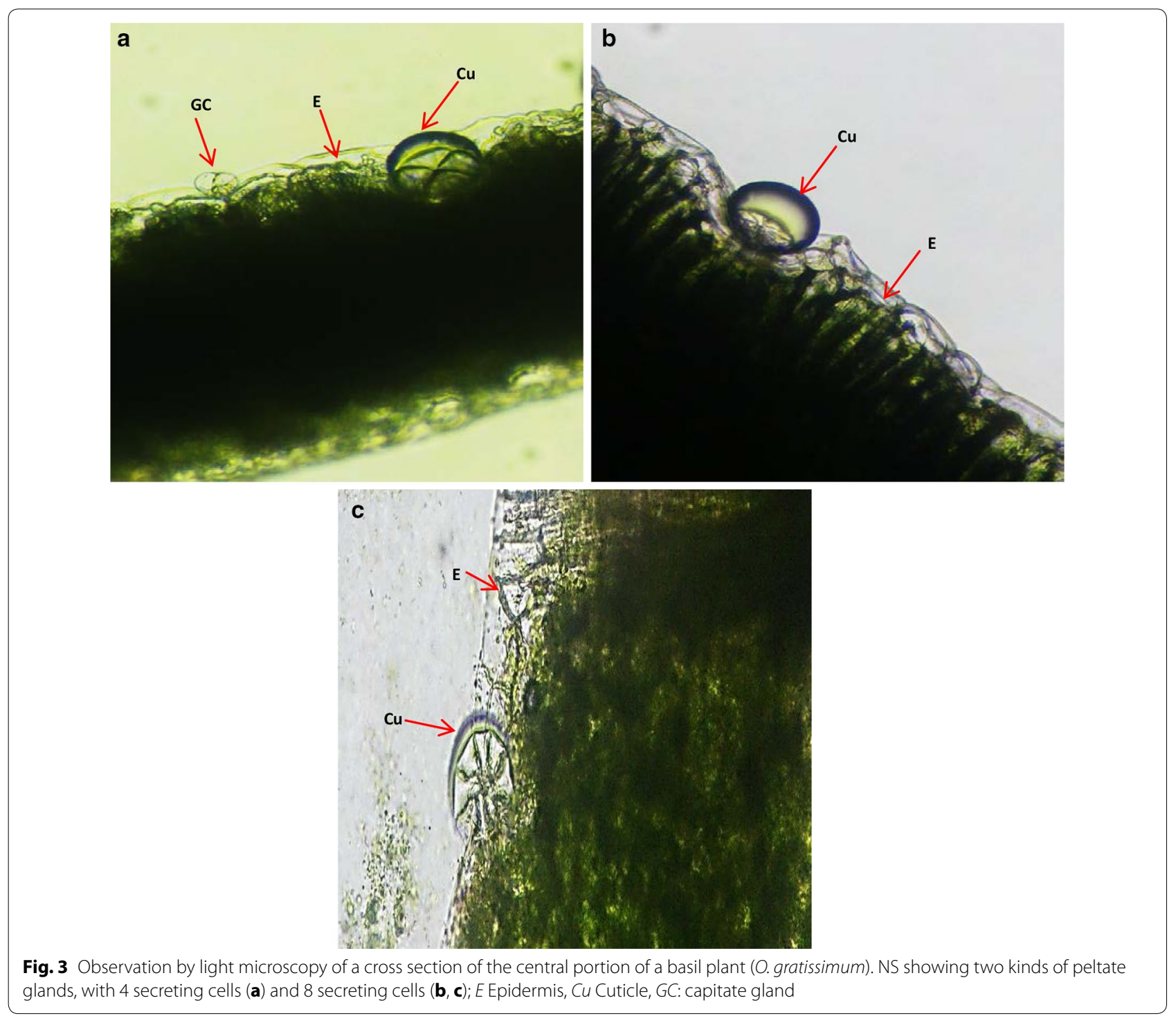

with a more or less wrinkled appearance mainly in mycorrhizal plants. This deflation let appear at the epidermis surface a glandular excavation with a diameter as that of an inflated glandular cavity in unstressed plant (between 75 and $78 \mu \mathrm{m}$ ) (Fig. 6).

In addition, Fig. 7 shows the gland location at the basal region (a) and apical region (b) of a basil plants cultivated under optimum conditions (mycorrhized unstressed plant). It is noted that there is no difference as regards the morphology of these glands whatever the section is (basal or apical); the glands are always present in a swollen form. Contrariwise, in the plant found in stressed conditions (non-mycorrhized stressed plant), a structural difference is observed between the glands according to their location in the sheet: the glands in the basal section was found to have a swollen appearance (Fig. 8a), while those located in the apical portion was found to have a deflated aspect, with a diameter of $58 \mu \mathrm{m}$ and leaving an excavation of a very large diameter (Fig. 6 also Fig. 8b) that can reach $80 \mu \mathrm{m}$ or more. This difference between the two sections of the sheet can be explained by the fact that the basal section, being closest to the stem, is the first to receive water and nutrients, thus contributing to adequate supply of water and nutrients to the cells in this section and therefore a more or less normal moisture balance of the cells. On the contrary, the other section of the sheet (apical) receives less supply of these elements, which causes a reduction of volume and deflation of glands. Note that we do not see any difference in the diameter of these glands according to their location. 

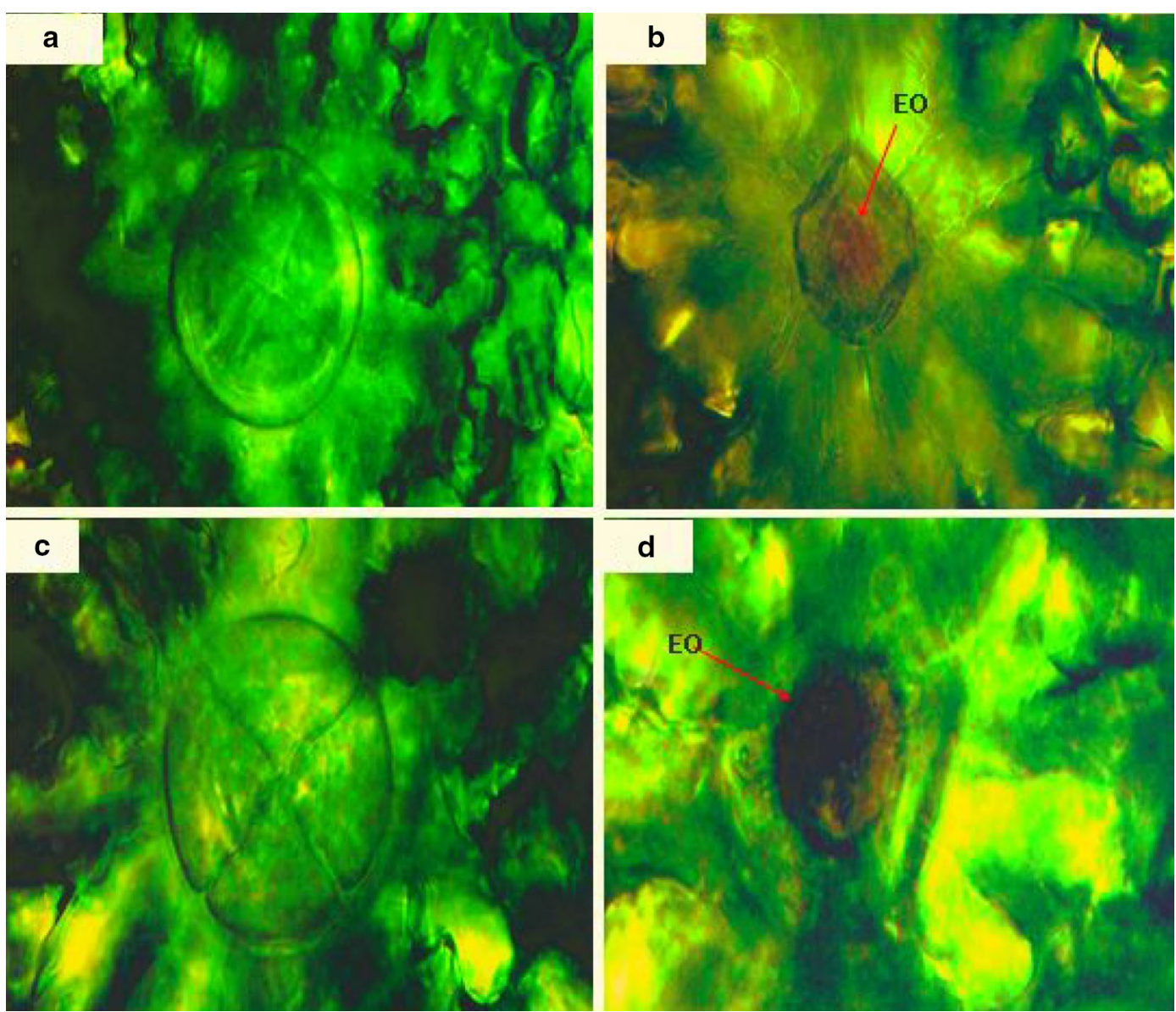

Fig. 4 Light microscopy observations of secretory glands realized at the ventral surface of basil leaves (O. gratissimum): NM.NS (a), NM.S (b), M.NS (c), and MS (d) (EO: essential oil)

\section{Composition of basil (O.gratissimum L.) essential oils} after inoculation with AMF and different irrigation systems The essential oil yield is strongly changed by the mycorrhization since found a higher synthesis in both cases stress and irrigation. This increase reaches values up to $37.5 \%$ more than those found in non-mycorrhizal plants (Table 2). Moreover, water stress did not show a significant influence on the essential oil synthesis, because we noticed a slight increase in EO levels. These results can be confirmed by the increase in the number and diameter of glandular hairs in basil leaves. From the composition viewpoint, the basil essential oils have 4 categories of molecules: monoterpene hydrocarbon, oxygenated monoterpenes, oxygenated sesquiterpenes, and hydrocarbon sesquiterpenes. The hydrocarbon monoterpenes, represented by the single molecule Azulene, have very low levels irrespective of the surrounding factor.

However, oxygenated monoterpenes have the major contribution to basil essential oils, with 5 molecules whose contents changed between $87 \%$ in NM.S plants and a maximum reached $97 \%$ in M.NS plants. The methyl chavicol is the major molecule of basil essential oils, with contents ranging between a maximum of $93 \%$ in MS plants and a minimum of $84 \%$ in NM.S plants. However, its isomer ( $t$-anethole) varies differently between stress and mycorrhizal conditions (Fig. 9), and water stress causes a reduction in the levels of this molecule, especially in non-mycorrhizal stressed plants (2\%). However, mycorrhizal causes an increase in the levels of this molecule with a maximum recorded in M.NS plants (8\%).

Hydrocarbon sesquiterpenes have the highest qualitative diversity with 9 molecules in NM.S plants and 8 molecules in the other treatments. Moreover, we note that the highest content of this family was found in the NM.S plants $(8.61 \%)$ with the appearance of two molecules (germacrene-D) whose contents are $1.76 \%$ and the nearly disappearance of Aristolene (0.05\%). However, this family of molecules has a very low abundance in M.NS plants with values $<2 \%$ of total yield. Moreover, the oxygenated 

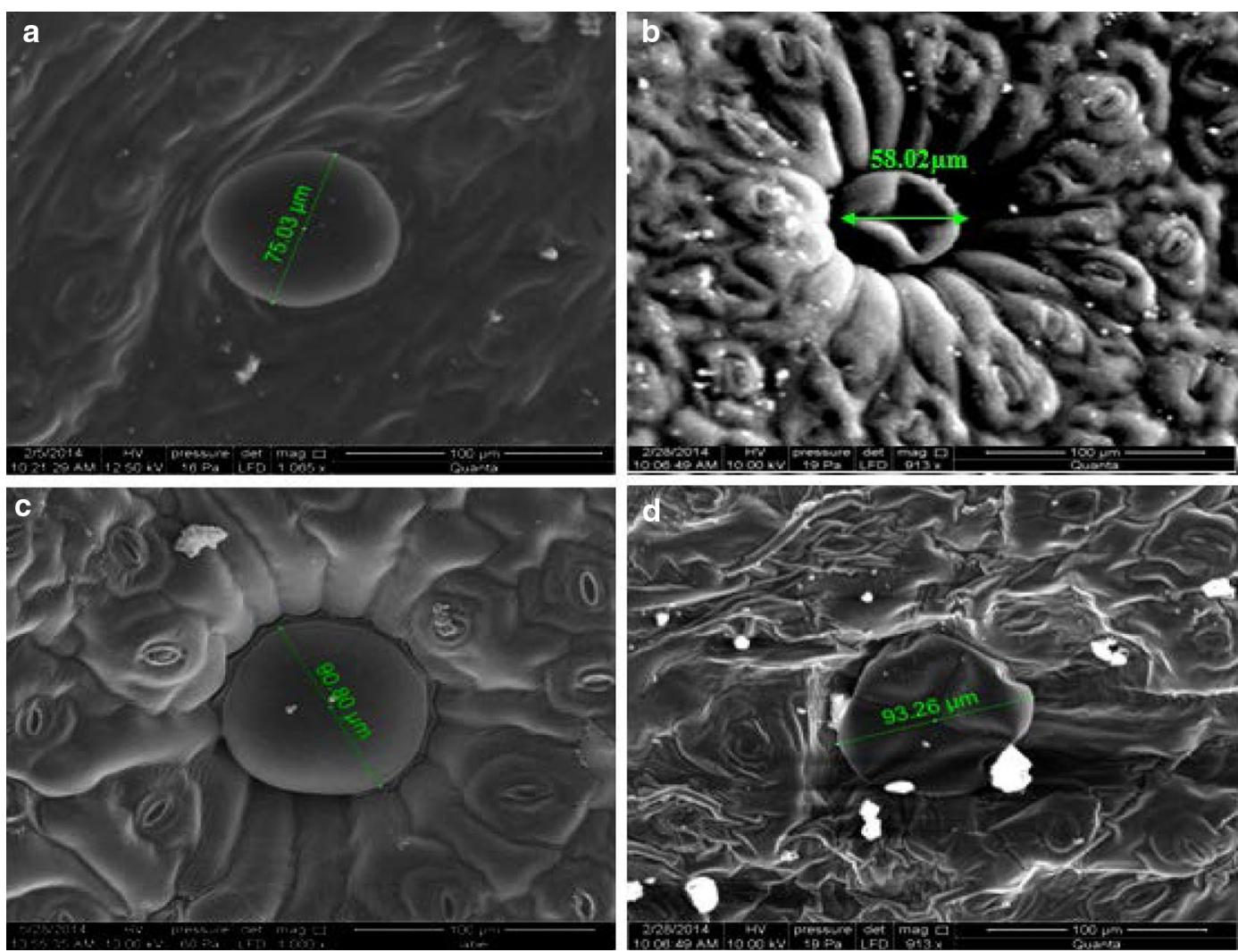

Fig. 5 Observation by environmental scanning electron microscope of the central portion of the basil leaves (O. gratissimum) from a plant: NM.NS (a), NM.S (b), M.NS (c), and MS (d)

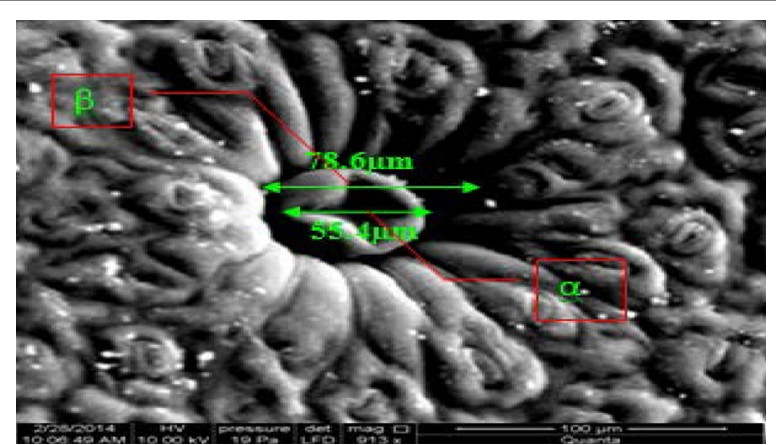

Fig. 6 Comparison of excavation glandular diameter in NM.S plant and its potential diameter in case of cuticle swelling

sesquiterpenes were represented by a single molecule (Cubenol), which appear in NM.S plants (0.2\%).

\section{Discussion}

The glandular trichome morphology is largely influenced by mycorrhizal and the hydric state of plant; the observations made in this study have demonstrated the existence of two types of peltate glands according to their shape: inflated glands and deflated glands. Mycorrhization provides for plants an optimal nutrition as well as hydric or mineral, allowing the leaves to receive the water and nutrients in roughly sufficient quantities. This water inlet provides a turgor state of epidermal cells and secretory cells of the gland, causing swelling of cavities and magnification.

In NM plants, the decrease of water content in leaves causes a plasmolysis of cells following the decrease of the water content at the glands, which leads to a decrease of their volume and deflation. This decrease of volume is even more pronounced in stress condition. These results do not confirm those obtained by Copetta et al. [2, 3] who did not observe significant differences in structures between the cavities of NM plants and those M plants.

Furthermore, we were able to highlight the presence of secreting glands having 4 cells and other with 8 cells. Light microscopy observations (Fig. 3) showed that the glands with pleated and deflated appearance have a reddish color, which allows us to conclude the presence of essential oil content. These results are in agreement with those of Werker et al. [35] who showed that basil (O. basilicum) may have a gland with 4 or more secreting cells, and the maturation of glands is determined by 

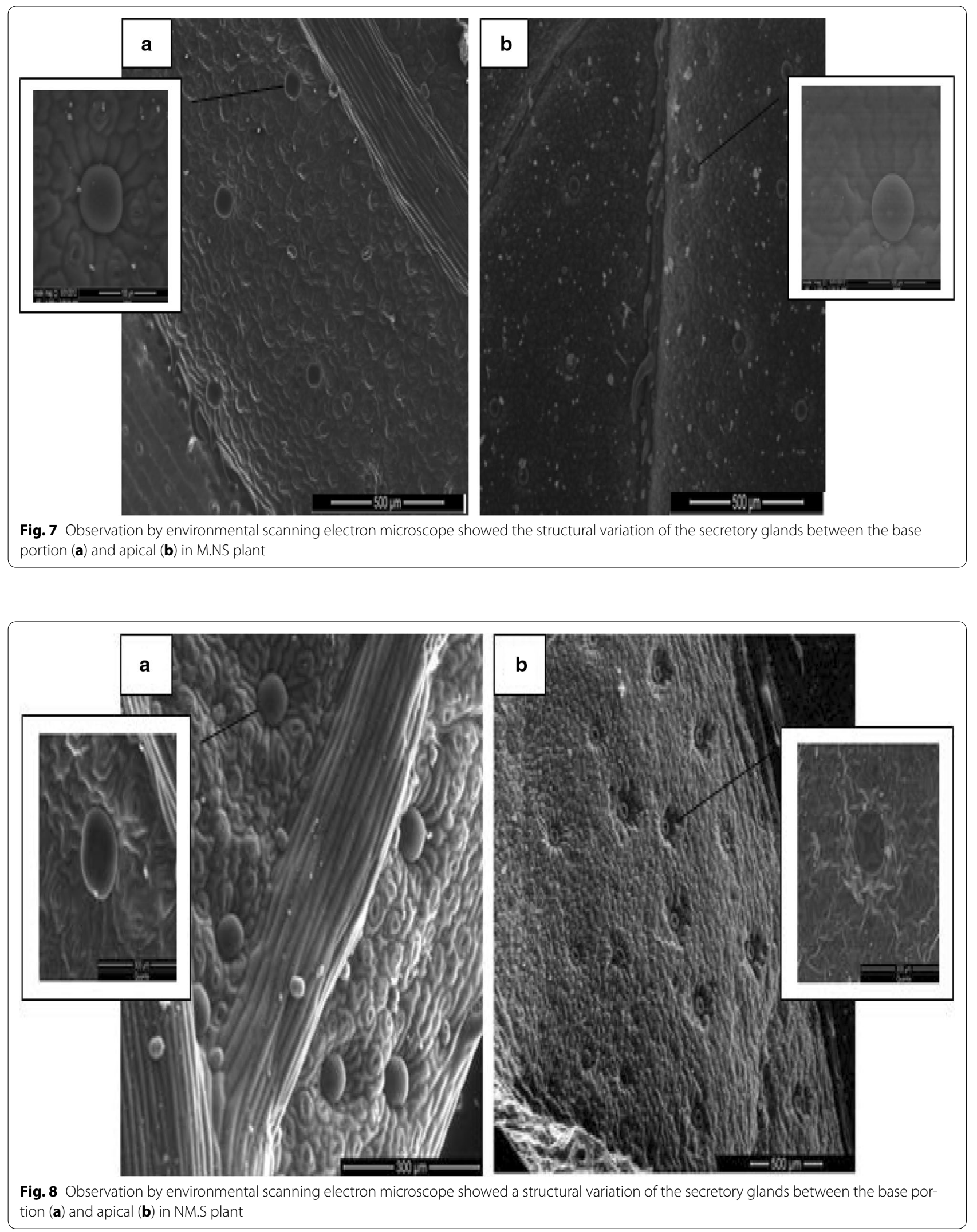
Table 2 Influence of mycorhization and water stress on essential oils yield and composition in O. gratissimum L

\begin{tabular}{|c|c|c|c|c|}
\hline Treatments & NM.NS & NM.S & M.NS & MS \\
\hline Oils content (\%) & $0.22 \pm 0.03 a$ & $0.24 \pm 0.02 \mathrm{a}$ & $0.3 \pm 0.1 b$ & $0.33 \pm 0.08 c$ \\
\hline \multirow[t]{2}{*}{ Components } & Peak area \% & & & \\
\hline & Hydrocarbons monoterpenes & & & \\
\hline \multirow[t]{2}{*}{ Azulene } & $0.44 \pm 0.02 \mathrm{a}$ & $0.89 \pm 0.03 b$ & $0.29 \pm 0.06 a$ & $0.23 \pm 0.07 a$ \\
\hline & Oxygenated monoterpenes & & & \\
\hline Eucalyptol & $2.02 \pm 0.08 a$ & $0.39 \pm 0.06 b$ & $0.74 \pm 0.11 \mathrm{c}$ & $0.88 \pm 0.05 c$ \\
\hline a-Campholene & $0.20 \pm 0.05 a$ & $0.26 \pm 0.03 a$ & $0.23 \pm 0.02 a$ & $0.13 \pm 0.02 b$ \\
\hline Methyl-chavicol & $85.26 \pm 0.32 \mathrm{a}$ & $84.38 \pm 0.72 \mathrm{a}$ & $86.40 \pm 0.62 a$ & $92.62 \pm 0.42 b$ \\
\hline Trans anethole & $4.25 \pm 0.22 a$ & $2.28 \pm 0.3 b$ & $8.31 \pm 0.41 c$ & $2.45 \pm 0.38 b$ \\
\hline Cis anéthole & $0.12 \pm 0.04 a$ & $0.08 \pm 0.03 a$ & $1.64 \pm 0.14 b$ & $0.15 \pm 0.05 a$ \\
\hline \multirow[t]{2}{*}{ Total } & $91.85 a$ & $87.38 b$ & $97.32 \mathrm{c}$ & $96.23 c$ \\
\hline & Hydrocarbons sesquiterpenes & & & \\
\hline Caryophyllene & $0.21 \pm 0.11 \mathrm{a}$ & $0.36 \pm 0.09 a$ & $0.11 \pm 0.02 b$ & $0.15 \pm 0.04 b$ \\
\hline Calarene & $0.50 \pm 0.15 a$ & $0.68 \pm 0.12 a$ & $0.18 \pm 0.14 b$ & $0.27 \pm 0.11 b$ \\
\hline a-Longipinene & $0.82 \pm 0.18 a$ & $1.37 \pm 0.09 b$ & $0.35 \pm 0.18 c$ & $0.71 \pm 0.16 a$ \\
\hline a-Caryophyllene & $0.52 \pm 0.19 a$ & $0.78 \pm 0.02 b$ & $0.31 \pm 0.16 a$ & $0.34 \pm 0.18 a$ \\
\hline Aristolene & $0.73 \pm 0.14 a$ & $0.05 \pm 0.2 \mathrm{a}$ & $0.33 \pm 0.08 b$ & $0.64 \pm 0.1 \mathrm{a}$ \\
\hline Germacrene-D & - & $1.76 \pm 0.18$ & - & - \\
\hline$\beta$ Cedrene & $0.21 \pm 0.11 \mathrm{a}$ & $0.38 \pm 0.09 a$ & $0.09 \pm 0.02 b$ & $0.16 \pm 0.08 a$ \\
\hline Aromadendrene & $0.21 \pm 0.13 a$ & $0.65 \pm 0.15 b$ & $0.11 \pm 0.09 a$ & $0.18 \pm 0.09 a$ \\
\hline Cadinene & $0.78 \pm 0.19 a$ & $2.38 \pm 0.09 b$ & $0.48 \pm 0.32 a$ & $0.84 \pm 0.11 a$ \\
\hline \multirow[t]{2}{*}{ Total } & $3.98 \mathrm{a}$ & $8.41 b$ & $1.96 \mathrm{c}$ & $3.29 \mathrm{a}$ \\
\hline & Oxygenated sesquiterpenes & & & \\
\hline Cubenol & - & $0.20 \pm 0.07$ & - & - \\
\hline
\end{tabular}

One-way analysis of variance was carried out for each parameter studied. Tukey's post hoc multiple mean comparison test was used to test for significant differences between treatments (at $p \leq 0.05 \%$ ). Univariate analysis was used to test significant differences in treatments, accessions and their interaction for an individual parameter. All statistical analyses were performed with IBM.SPSS statistics, Version 19.The results of each experiment (biochemical essays) were repeated three times and (20 times for mycorrhizal intensity essays)

The values are the average of 3 determinations, and the values followed by different letters are significantly different $(p \leq 0.05)$

the folding of the cuticle that occurs when the secretory cells stop secreting the essential oils. They also noticed that the older leaves have glands with a pleated appearance and are sunken. Contrariwise, Gang et al. [5] have not observed the presence of glands with 8 cells, and they say that the pleated glands do not present a terpenoid content. According to the same authors, the folding allows a quadratic subdivision of the cuticle as a result of the presence of 4 secreting cells, and they indicate the non-maturation of glands since at the time of filling of this cuticular cavity by essential oils, this quadratic division tends to disappear and these glands become less abundant.

In addition, according to our results, the degree of maturation of the gland is related to essential oil synthesis and cuticular cavities filled by these oils, leading to an important increase in gland diameter, regardless of the degree of fold, and also this aspect is linked to the water and nutritional status of plants.
This finding is confirmed by the position of glands in leaf. The glands in basal section have an inflated appearance and those of the apical section have a deflated aspect when the plant is under water stress condition. Moreover, the measurement of excavation diameter depends on the gland location at the leaf. The diameter of this latter can reach about $78.6 \mu \mathrm{m}$, diameter that gland may have when is swelling (Fig. 6b).

\section{Effect on essential oil yield and composition}

The essential oil yield is strongly influenced by the mycorrhization, since found a higher synthesis regardless the hydration level of plant (stress or irrigation). Water stress also shows a slight increase in essential oil contents. However, the combined treatment (stress and mycorrhization) can increase the EO yield about 50\% more than NM.NS. These results confirm those of Copetta et al. [2,3] which showed that this increase in mycorrhizal plants may be due to a defensive response to fungal colonization, since 


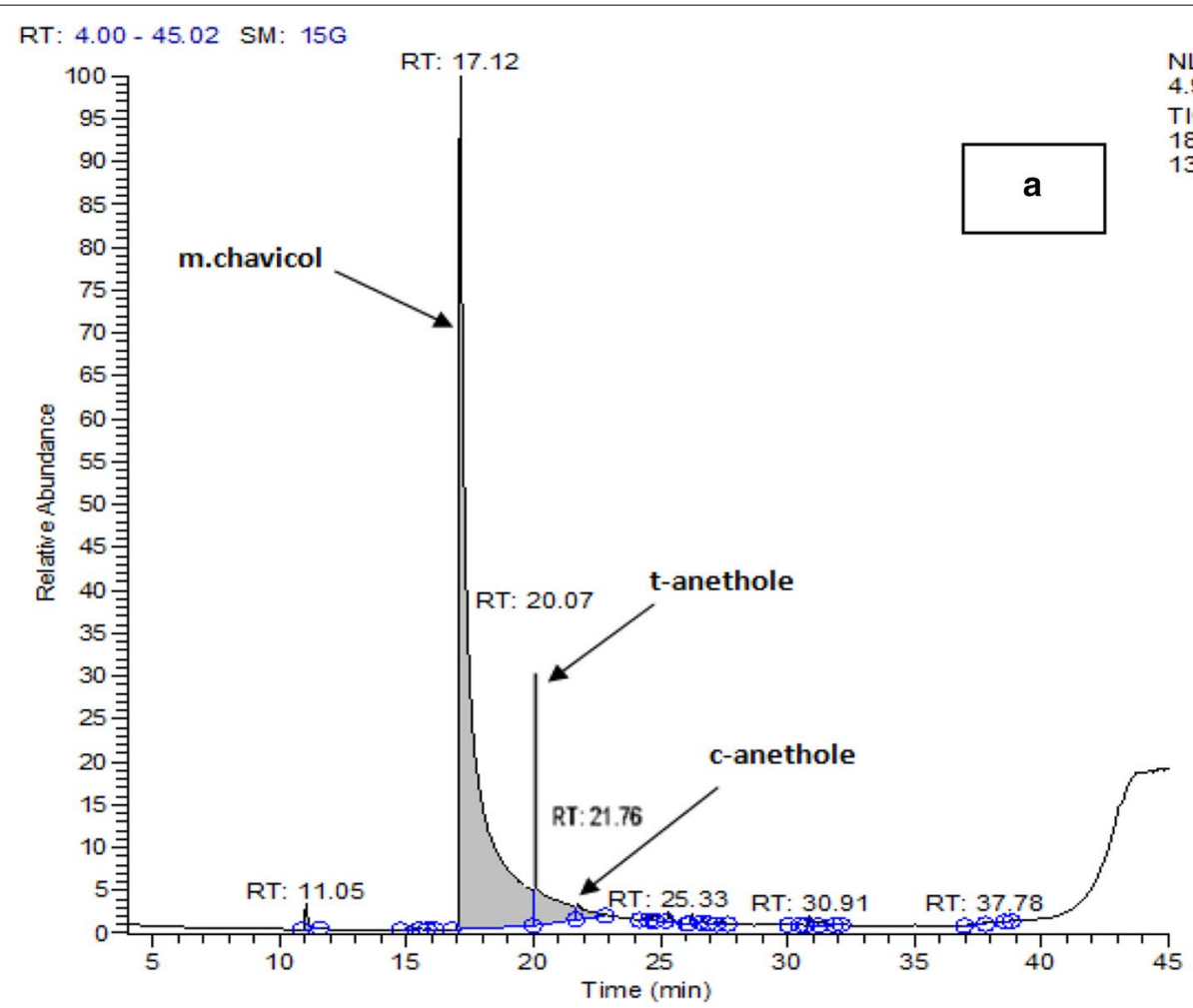

RT: $4.00-45.00$ SM: $15 \mathrm{G}$

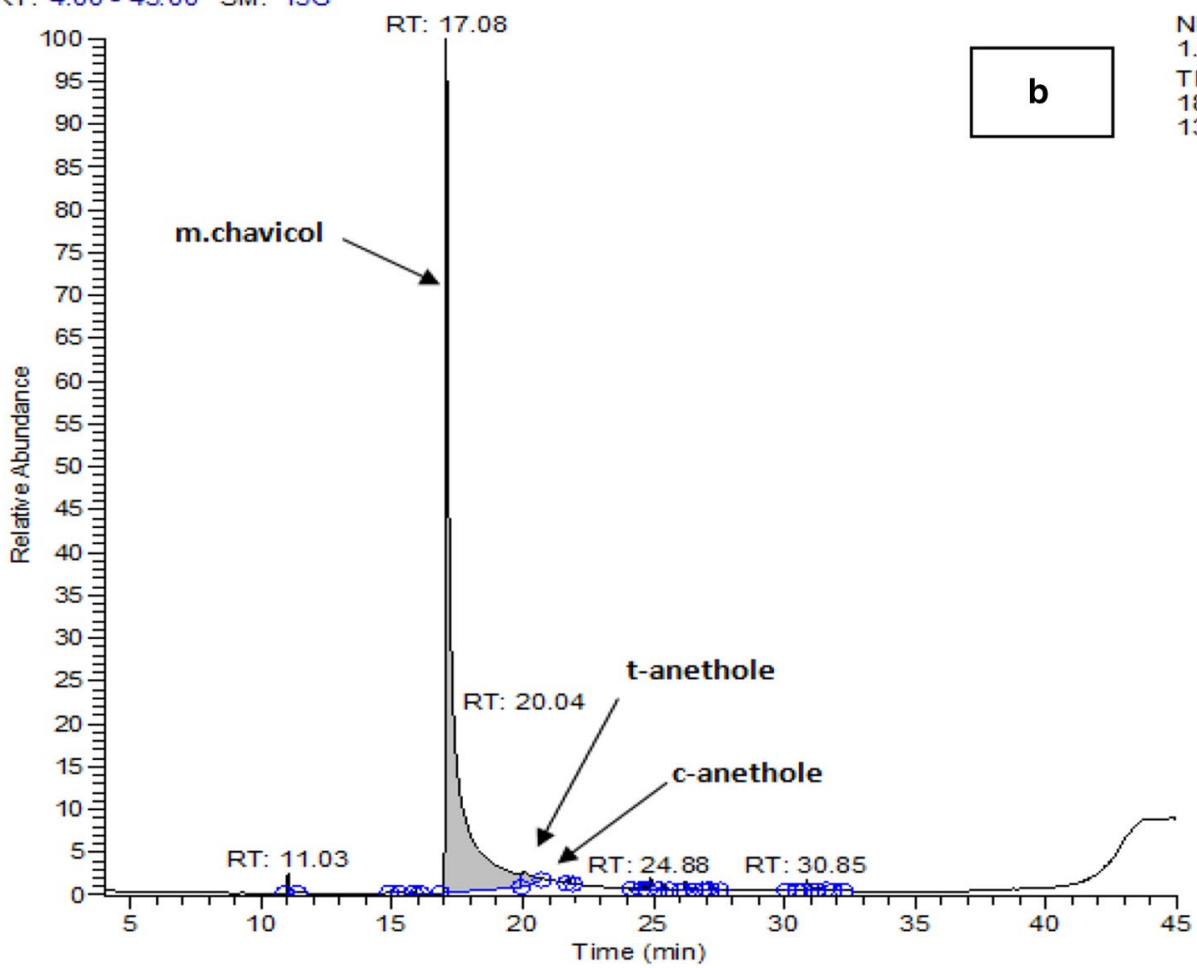

Fig. 9 Chromatograms of essential oils extracted from O. gratissimum L. plants: a M.NS, b MS 
several molecules of these essential oils have fungicidal properties. Furthermore, the increase can also be attributed to a change in the secondary metabolism of plants and the number of gland leaves confirming the results of Zolfaghari et al. [37] and Freitas et al. [4], which recorded an increase in essential oil yields of $M$. arvensis and Mentha piperita L. plants inoculated with mycorrhizal fungi. The colonization by AM fungi stimulates the production of these glands probably by increasing endogenous hormone levels particularly AIA, cytokinin, and GA. These results are confirmed also by Hazzoumi et al. [10, 11].

Considering essential oil groups, we see that mycorrhization generates an increase in oxygenated monoterpene level, both in stress condition or not. By contrast, hydrocarbon sesquiterpenes decrease remarkably. These results go in the same way as those of Copetta et al. [2, 3] who have shown that basil plants (O. basilicum L.) inoculated by Gigaspor arosea and Gigaspora margarita induce a quantitative and not qualitative variation in the essential oil constituents, with an increase in oxygenated monoterpene level and the diminution of hydrocarbon sesquiterpenes. In the same way, Khaosaad et al. [15] showed in two species of basil (O. vulgare and O. basilicum) that the inoculation with G. rosea and G. mosseae lead to an increase in essential oil yield and changed the composition. This increase is related to the abundance of secretory glands and their maturation stage (secretory or postsecretory stage) according to Sudria et al. [31].

The influence of mycorrhization in the levels of essential oil groups is mainly due to the change in the contents of different molecules constitutive of this group. Following inoculation by G. intraradices, the increase is mostly influenced by the main compounds variation ( $\mathrm{m}$-chavicol and $t$-anethole); these results are confirmed by Copetta et al. [2] who showed a significant increase in levels of some molecules like eucalyptol and linalool in O. basilicum inoculated by G. Margarita. Moreover, in studies realized on $M$. arvensis, Khaliq and Janardhanan [16], Gupta et al. [8], and Freitas et al. [4] showed a relationship between the presence of AMF and some change in essential oil composition. Similar results were confirmed by Kapoor et al. [13] on Coriandrum sativum, and Nemec and Lund [22] on Citrus Jambhiri inoculated by G. intraradices.
Our results also show that water stress causes a slight increase in essential oil yield; this increase may be a result of the activation of certain enzymes involved in the synthesis of some secondary metabolites implicated in defense. These results are in agreement with those of Khalid [14] who reported an increase in essential oil yield after applying water stress on Ocimum basilicum L., Ocimum americanum L., Cymbopogon nardus L., and Cymbopogon pendulm L. plants.

Furthermore, we find that water stress causes a decrease in oxygenated monoterpene levels and a very important increase in hydrocarbon sesquiterpenes. These results are consistent with those of Simon et al. [28] who noticed an increased levels of linalool and methyl chavicol after applying water stress on basil plants (O. basilicum). Moreover, Khalid [14] reported high levels of methyl chavicol after applying water stress on $O$. basilicum, while in O. americanum L. plants, he recorded a decrease in levels of this molecule. Eucalyptol slightly decreases after water stress in O. basilicum and O. americanum, while the cadinene contents increase, which is consistent with our results.

\section{Influence of mycorrhization in the presence or absence of water stress on the two isomers: methyl chavicol and trans-anethole}

Essential oils (O. gratissimum) are characterized by $\mathrm{m}$-chavicol as chemotype, with the presence of its isomer ( $t$-anethole). These two isomers are different only in the double bond of the propenyl chain, and we can find this natural isomer in many EO: (Artemisia dracunculus L.), basil (O. basilicum L.), and (Foeniculum vulgare) $[7,18]$ but with different contents. This difference is mainly due to the (O-methyl transferase) enzyme, which uses chavicol and trans-anol as substrate to produce methyl chavicol and trans-anethole, respectively $[7,19]$.

This variation in the content of the two isomers and the absence of trans-anol suggest that in O. gratissimum L., the synthesis pathway of trans-anethole pass through direct isomerization of methyl chavicol (Fig. 10) probably through an enzyme complex and not by the transformation of trans-anol as already
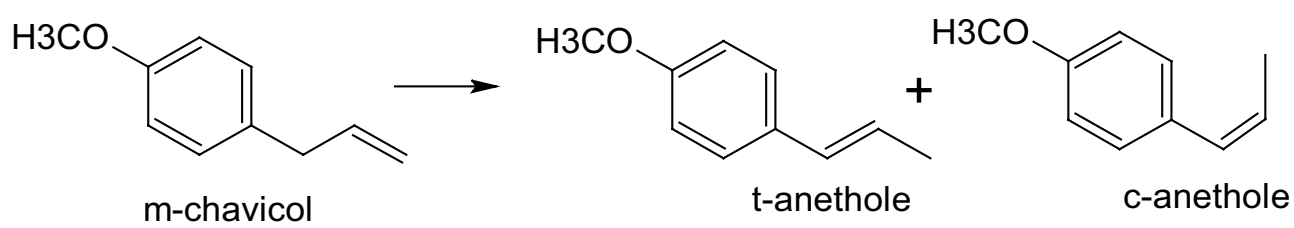

Fig. 10 Isomerization of m-chavicol to anethole according to Kishore and Kannan [17] 
suggested by Gross et al. [7]. In vitro catalysis of this reaction is possible and widely used in the food industry [17, 27] Fig. 9. Low levels of cis-anethole found in our extracts can be attributed to the instability of the cis configuration and they confirm the presence of a direct isomerization.

Furthermore, our results show that these two isomers progress in opposite ways: the increase of a molecule causes a decrease of its isomer and vice versa (Table 2; Fig. 9). However, Hazzoumi et al. [11] have shown that exogenous application of GA $70 \mathrm{ppm}$ on basil plants $(O$. gratissimum) causes the isomerization of $\mathrm{m}$-chavicol to $t$-anethole, by the variation in the level of a specific enzyme who assured a direct isomerization of $\mathrm{m}$-chavicol to $t$-anethole (changed the double bond position), and this enzyme is influenced by the plant growth regulator. Furthermore, Martín-Rodríguez et al. [21] have shown the existence of a correlation between mycorrhizal development and synthesis of GA in tomato. These authors noted an increase in endogenous GA level in the roots, and over expression of genes encoding enzymes involved in the biosynthesis of GA after mycorrhizal infection. This hypothesis can be confirmed by the results obtained in NM plants in which the isomerization phenomenon is not observed.

\section{Conclusion}

The histological study of O. gratissimum L. peltate glands shows clear structural differences when the plants are subject to mycorrhization or water stress. However. In case of non-mycorrhization, there is deflation of extracellular cavities and a decrease in diameter which causes an increase in the concentration of EO. Water stress leads to the same findings, but this effect is attenuated in case of mycorrhization.

These two factors also influence the synthesis of essential oils: Water stress and mycorrhizal symbiosis cause variation in yields and compostion. Mycorrhization causes increase in essential oil yield regardless of the hydric state of the plant. Furthermore, the synthesis of the majority compound, methyl chavicol, increases in mycorrhizal stressed plants (93\%) and decreases in nonmycorrhizal stressed plants (84\%), while its isomer, transanethole, increases in NM.NS (8\%) and diminishes in NM.S plants (2\%).

\section{Abbreviations \\ AMF: arbuscular mycorrhizal fungi; $m$-chavicol: methyl chavicol; $t$-anethole: trans-anethole; GA: gibberellic acid; IAA: indole 3-acetic acid; EO: essential oil; M.NS: mycorrhizal unstressed; MS: mycorrhizal stressed; NM.NS: non-mycorrhi- zal unstressed; NM.S: non-mycorrhizal stressed.}

\section{Authors' contributions}

YM and KAJ are participated in the data processing, the design of the study, performed the statistical analysis and the manuscript drafting. All authors read and approved the final manuscript.
Competing interests

The authors declare that they have no competing interests.

Availability of data and materials

All the data and materials are available for the journal and other authors.

\section{Publisher's Note}

Springer Nature remains neutral with regard to jurisdictional claims in published maps and institutional affiliations.

Received: 27 December 2016 Accepted: 10 April 2017

Published online: 07 August 2017

\section{References}

1. Bandurska H. Akumulacja wolnej proliny jako przejaw metabolicznej reakcji rooelin na dziaanie stresu wodnego. Wiad Bot. 1991;35:35-46

2. Copetta $A$, Lingua $G$, Berta $G$. Effects of three AM fungi on growth, distribution of glandular hairs, and essential oil production in Ocimum basilicum L. var. Genovese. Mycorrhiza. 2006;16:485-94.

3. Copetta A, Lingua G, Berta G, Bardi L, Masoero G (2006) Three arbuscular mycorrhizal fungi differently affect growth, distribution of glandular trichomes and essential oil composition in Ocimum basilicum var. Genovese. In: Proceedings of the 1st international symposium on the Labiatae: Advances in Production, Biotechnology and Utilisation, vol 723. 2006; p. $151-56$.

4. Freitas MSM, Martins MA, Vieira IJC. Yield and quality of essential oils of Mentha arvensis in response to inoculation with arbuscular mycorrhizal fungi. Pesqui Agro pecu Bras. 2004;39:887-94.

5. Gang DR, Wang J, Dudareva N, Nam KH, Simon JE, Lewinsohn E, Pichersky E. An investigation of the storage and biosynthesis of phenylpropenes in sweet basil. Plant Physiol. 2001;125:539-55.

6. Gershenzon J, Maffei M, Croteau R. Biochemical and histochemical localization of monoterpene biosynthesis in the glandular trichomes of spearmint (Menthaspicata). Plant Physiol. 1989;89:1351-7.

7. Gross M, Jacob F, Nativ D, Olga L, Yael C, Einat B, Uzi R, Eli P, Efraim L. Biosynthesis of estragole and $t$-anethole in bitter fennel (Foeniculum vulgare Mill. var. vulgare) chemotypes. Changes in SAM:phenylpropene Omethyl transferase activities during development. Plant Sci. 2002;163:1047-53.

8. Gupta ML, Prasad A, Ram M, Kumar S. Effect of the vesicular-arbuscular mycorrhizal (VAM) fungus Glomus fasciculatum on the essential oil yield related characters and nutrient acquisition in the crops of different cultivars of menthol mint (Mentha arvensis) under field conditions. Bioresour Technol. 2002:81:77-9.

9. Hayman PE. Improved procedures for clearing and staining parasite and vesiculaire-arbiscular mycorrhizal fungi for rapid assassment of infection trans. Brit Mycol Soc. 1970;55:158-61.

10. Hazzoumi Z, Moustakime Y, Elharchli E, Joutei KA. Effect of arbuscular mycorrhizal fungi (AMF) and water stress on growth, phenolic compounds, glandular hairs, and yield of essential oil in basil (Ocimum gratissimum L.). Chem Biol Technol Agric. 2015;2:10.

11. Hazzoumi Z, Moustakime Y, Khalid A. Effect of gibberellic acid (GA), indole acetic acid (IAA) and benzyl-amino-purine (BAP) on the synthesis of essential oils and the isomerization of methyl-chavicol and trans-anethole in Ocimum gratissimum L. Springer Plus. 2014;3:321.

12. Hendawy SF, Khalid KA. Response of sage (Salvia officinalis L.) plants to zinc application under different salinity levels. J Appl Sci Res. 2005;1(2):147-55

13. Kapoor R, Giri B, Mukerji KG. Improved growth and essential oil yield and quality in Foeniculu mvulgare mill on mycorrhizal inoculation supplemented with P-fertilizer. Bioresour Technol. 2004;93:307-11.

14. Khalid KhA. Influence of water stress on growth, essential oil, and chemical composition of herbs (Ocimum sp.). Int Agrophys. 2006;20:289-96.

15. Khaosaad T, Vierheilig H, Nell M, Zitterl-Eglseer K, Novak J. Arbuscular mycorrhiza alter the concentration of essential oils in oregano (Origanum sp., Lamiaceae). Mycorrhiza. 2006;16:443-46.

16. Khaliq A, Janardhanan KK. Influence of VAM Fungi on the productivity of cultivated mints. Lucknow J Medi Arom PI Sci. 1997;19:7-10 
17. Kishore D, Kannan S. Catalytic isomerization of estragole to anethole over hydrotalcites and HT-like compounds. J Mol Catal A. 2006;244:83-92.

18. Koeduka T, Baiga TJ, Noel JP, Pichersky E. Biosynthesis of t-Anethole in Anise: characterization of t-anol/isoeugenol synthase and an O-Methyltransferase specific for a C7-C8 propenyl side chain. Plant Physiology. 2009;149:384-94.

19. Lewinsohn E, Ziv-Raz I, Dudai N, Tadmor Y, Lastochkin E, Larkov AO, David C, Uzi R, Eli P, Eran P, Yuval S. Biosynthesis of estragole and methyl-eugenol in sweet basil (Ocimum basilicum L.). Developmental and chemotypic association of allylphenol O-methyltransferase activities. Plant Sci. 2000;160:27-35.

20. Loveys BR, Rorinson SP, Bropl JJ, Chacko EK. Mango sapburn: components of fruit sap and their role in causing skin damage. Aust J Plant Physiol. 1992;19:449-57.

21. Martín-Rodríguez JÁ, Ocampo JA, Molinero-Rosales N, Tarkowská D, Ruíz-Rivero O, García-Garrido JM. Role of gibberellins during arbuscular mycorrhizal formation in tomato: new insights revealed by endogenous quantification and genetic analysis of their metabolism in mycorrhizal roots. Physiol Plant. 2014;154(1):66-81.

22. Nemec S, Lund E. Leaf volatiles of mycorrhizal and non mycorrhizal Citrus jambhiri Lush. J Essent Oil Res. 1990;2:287-97.

23. Polonsky J, Bhatnagar SC, Griffiths DC, Pickett JA, Woodcock CM. Activity of quassinoids as antifeedants against aphids. J Chem Ecol. 1989;15:993-8.

24. Pozo M, Azcón-Aguilar C. Unraveling mycorrhiza-induced resistance. Curr Opin Plant Biol. 2007;10:393-8.

25. Rapparini F, Llusia J, Penuelas J. Effect of arbuscular mycorrhizal (AM) colonization on terpene emission and contents of Artemisia annua $\mathrm{L}$. Plant Biol. 2008;10:108-22.

26. Shao HB, Chu LY, Jaleel CA, Zhao CX. Water-deficit stress-induced anatomical changes in higher plants. C R Biol. 2008;331:215-25.

27. Sharma SK, Srivastava VK, Pandya PH, Jasra RV. Solvent-free isomerization of methyl chavicol to trans-anethole using transition metal complexes as catalysts. Catal Commun. 2005;6:205-9.
28. Simon L, Bousquet J, Levesque RC, Lalonde M. Origin and diversification of endomycorrhizal fungi and coincidence with vascular land plants. Nature. 1993;363:67-9.

29. Singh M, Ramesh S, Kumar S, Kukreja AK. Effect of irrigation and nitrogen on herbage, oil yield and water-use efficiency in rosemary grown under semi-arid tropical conditions. J Med Aromat Plant Sci. 2000;22(1B):659-62.

30. Solinas V, Deiana S, Gessa C, Pistidda C. Reduction of the Fe(III)-desferrioxamine-B complexes by caffeic acid: a reduction mechanism of biochemical significance. Soil Biol Biochem. 1996;28(4-5):649-54.

31. Sudria C, Piñol MT, Palazón J, Cusidó RM, Vila R, Morales C, Bonfill M, Cañigueral S. Influence of plant growth regulators on the growth and essential oil content of cultured Lavandula dentata plantlets. Plant Cell Tissue Organ Cult. 1999;58:177-84.

32. Trouvelot A, Kough JL, Gianinazzi-Pearson V. Meesure du taux de mycorhization VA d'un système radiculaire. Recherche des méthodes d'estimation ayant une signification fonctionnelle. In: Bay G-P, Gianinazzi S, editors. Physiological aspect of mycorrizea. Paris: INRA; 1986. p. 217-21.

33. Vierheilig H, Gagnon H, Strack D, Maier W. Accumulation of cyclohexenone derivatives in barley, wheat and maize roots in response to inoculation with different arbuscular mycorrhizal fungi. Mycorrhiza. 2000;9:291-3

34. Werker E. Trichome diversity and development. Adv Botanical Res. 2000;31:1-35

35. Werker E, Putievsky E, Ravid U, Dudai N, Katzir I. Glandular hairs and essential oil in developing leaves of Ocimum basilicum L. (Lamiaceae). Ann Bot. 1993;71:43-50

36. Zehtab-Salmasi S, Javanshir A, Omidbaigi R, Alyariand H, GhassemiGolezani K. Effects of water supply and sowing date on performance and essential oil production of anise (Pimpinella anisum L.). Acta Agron Hung. 2001:49(1):75-81.

37. Zolfaghari M, Nazeri V, Sefidkon F, Rejali F. Effects effect of arbuscular mycorrhizal fungi on plant growth and essential oil contents and composition of Ocimum basilicum L. Iran J Plant Physiol. 2013;3(2):643.

\section{Submit your manuscript to a SpringerOpen ${ }^{\circ}$ journal and benefit from:}

- Convenient online submission

- Rigorous peer review

- Immediate publication on acceptance

- Open access: articles freely available online

- High visibility within the field

- Retaining the copyright to your article 